\title{
Enhanced Laser Desorption/lonization Mass Spectrometric Detection of Gold Nanoparticles in Biological Samples Using the Synergy Between Added Matrix and the Gold Core
}

\author{
Alyssa L. M. Marsico, Gokhan S. Elci, Daniel Moyano, Gulen Yesilbag Tonga, Bradley \\ Duncan, Ryan Landis, Vincent M. Rotello, Richard W. Vachet* \\ Corresponding Author \\ *Richard W. Vachet: e-mail, rwvachet@chem.umass.edu; phone, (+1) 413-545-2733; \\ fax, (+1) 413-545-4490. \\ Department of Chemistry, University of Massachusetts, Amherst, Massachusetts 01003, \\ United States
}

\section{Table of Contents}

Figure S1: LDI and MALDI of amino acid AuNPs; page 2

Figure S2: MALDI analysis of various AuNPs using different concentrations of matrix; page 2

Figure S3: Structures of peaks seen in the MALDI spectrum of the Phe AuNPs; page 3

Figure S4: MALDI analysis of a mixture of a zwitterionic AuNP and Bradykinin; page 3

Figure S5: Example calculations of concentrations of different size AuNPs needed to give a specific ligand concentration and a table of values as well; page 4

Figure S-6: Example mass spectra of AuNPs analyzed by both LDI and MALDI and free ligands analyzed by MALDI; page 5

Figure S7: MALDI analyses of mixtures of zwitterionic AuNPs and zwitterionic free ligands; page 6

References: Page 6 
a)

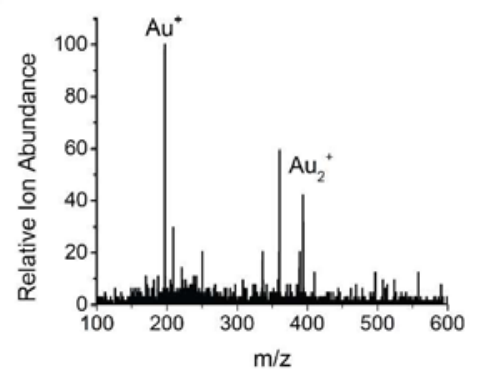

b)

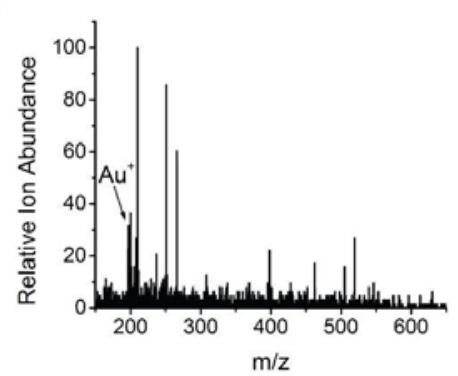

c)

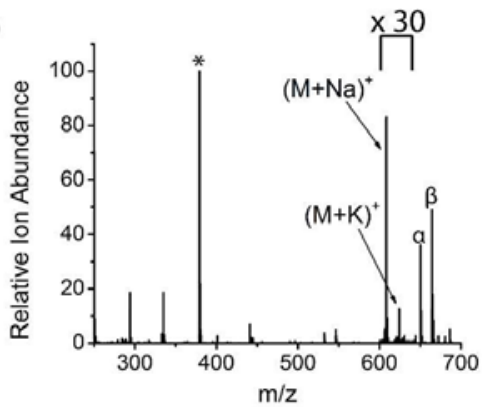

Figure S1. a) LDI mass spectrum of 0.5 pmol Arg NPs. b) LDI mass spectrum of $0.5 \mathrm{pmol}$ Phe NPs. c) MALDI mass spectrum of of $0.5 \mathrm{pmol}$ Phe NPs using $2.5 \mathrm{mg} / \mathrm{mL}$ CHCA. Black asterisks mark matrix peaks while $\alpha$ and $\beta$ mark peaks from by-products from the synthesis of the Phe NP ligands. These by-products are ligands that still have a t-butyl group, which is used as a protecting group, attached. Structures can be seen in Figure S-3.

a)

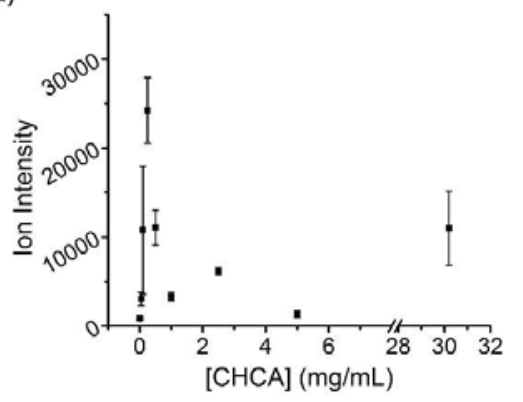

b)

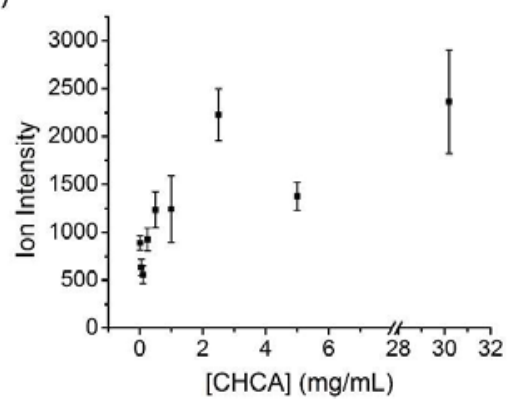

c)

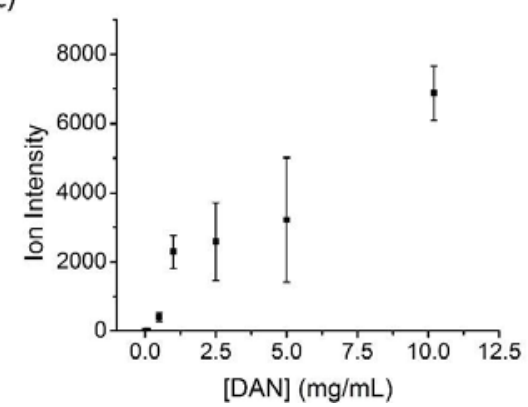

Figure S2. MALDI ion intensities at various matrix concentrations for a) 1 pmol of TTMA AuNPs and b) 1 pmol of TEGOH AuNPs using CHCA, and for c) 1 pmol of ZNP2 AuNPs using DAN. In most cases, higher matrix concentrations give rise to higher ion signal, yet lower matrix concentrations could be used to maintain ionization/detection selectivity of the AuNPs in the presence of other molecules. 

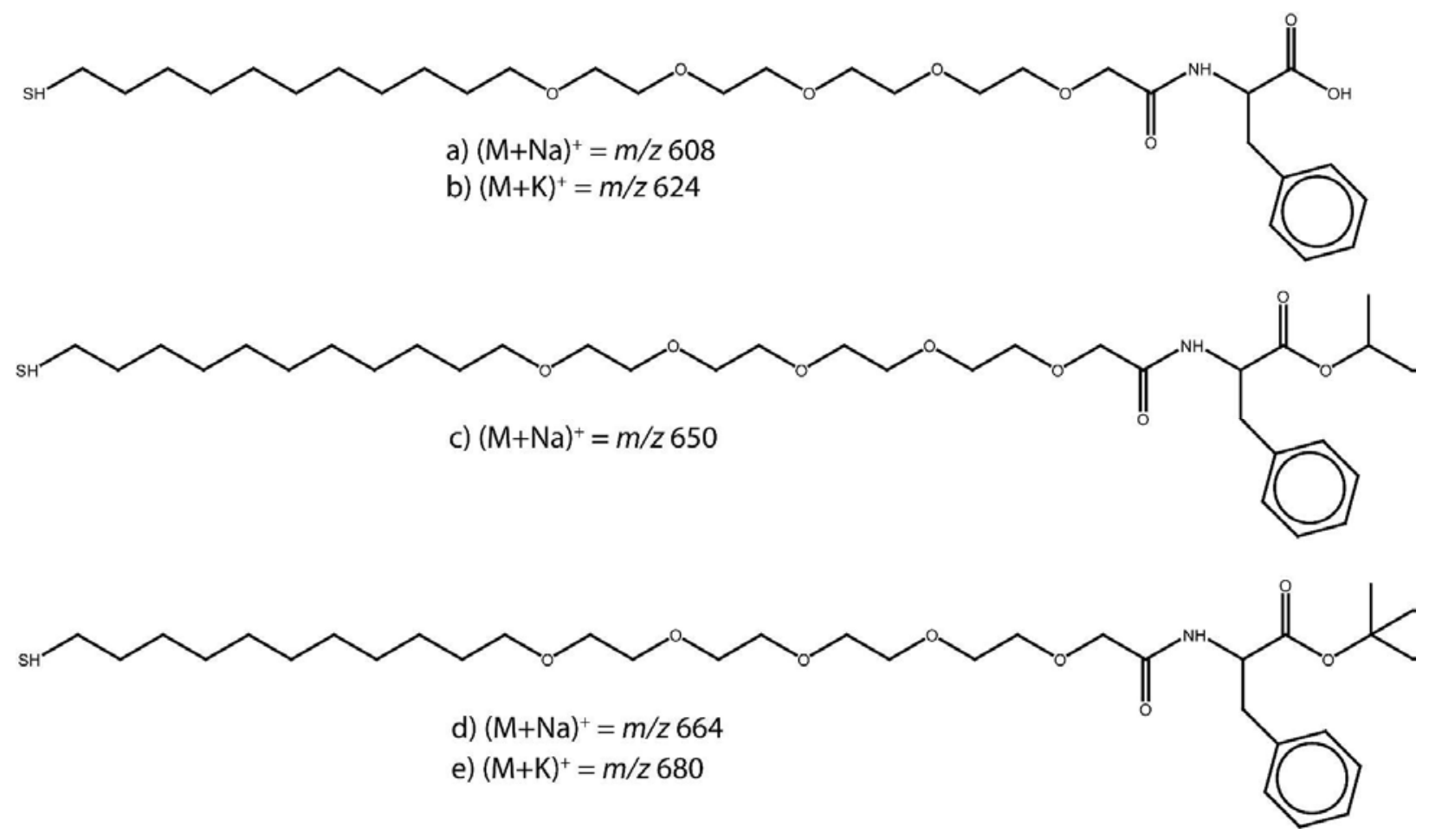

Figure S3. Structures of peaks seen in the MALDI mass spectrum of Phe AuNPs, a) and b) phenylalanine ligand, c) a fragment of the t-butyl derivatized Phe ligand and d) and e) a byproduct of the synthesis of phenylalanine ligands with an added t-butyl group, which is used as a protecting group in the synthesis. These structures represent peaks seen in Figure 4 of the main text.

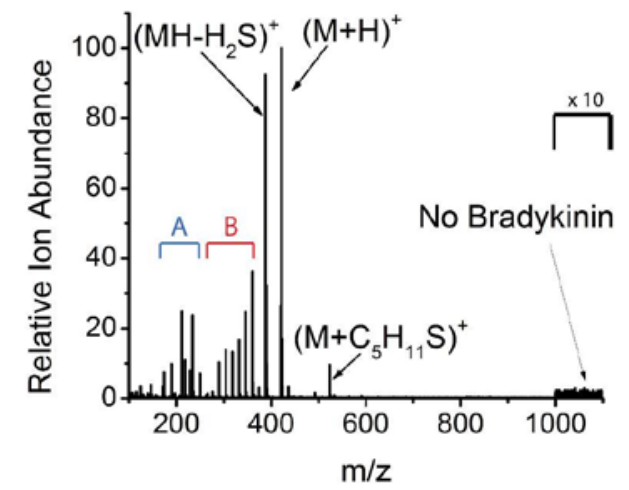

Figure S4. Mass spectrum of a mixture of $1 \mu \mathrm{M}$ TTMA AuNPs and $80 \mu \mathrm{M}$ bradykinin using 0.1 $\mathrm{mg} / \mathrm{mL} \mathrm{CHCA}$. 
a)

\begin{tabular}{|c|c|c|}
\hline Au Core Size & Calculation & [AuNP] \\
\hline $2 \mathrm{~nm}$ & $\frac{80 \text { ligands }}{1 \mathrm{NP}}=\frac{80 \mu M}{[2 \mathrm{nmAuNP}]}$ & $1 \mu \mathrm{M}$ \\
\hline $4 \mathrm{~nm}$ & $\frac{300 \text { ligands }}{1 \mathrm{NP}}=\frac{80 \mu M}{[4 \mathrm{nmAuNP}]}$ & $267 \mathrm{nM}$ \\
\hline $8 \mathrm{~nm}$ & $\frac{1,200 \text { ligands }}{1 \mathrm{NP}}=\frac{80 \mu M}{[8 \mathrm{nmAuNP}]}$ & $66.7 \mathrm{nM}$ \\
\hline
\end{tabular}

b)

\begin{tabular}{|c|c|c|c|}
\hline Au Core Size & Ligands on NP & [Ligand] $(\mu \mathrm{M})$ & [AuNP] \\
\hline \multirow{6}{*}{$2 \mathrm{~nm}$} & \multirow{6}{*}{80 ligands } & 5 & $62.5 \mathrm{nM}$ \\
\hline & & 10 & $125 \mathrm{nM}$ \\
\hline & & 20 & $250 \mathrm{nM}$ \\
\hline & & 40 & $500 \mathrm{nM}$ \\
\hline & & 80 & $1 \mu \mathrm{M}$ \\
\hline & & 160 & $2 \mu \mathrm{M}$ \\
\hline \multirow{6}{*}{$4 \mathrm{~nm}$} & \multirow{6}{*}{300 ligands } & 5 & $16.7 \mathrm{nM}$ \\
\hline & & 10 & $33.3 \mathrm{nM}$ \\
\hline & & 20 & $66.7 \mathrm{nM}$ \\
\hline & & 40 & $133 \mathrm{nM}$ \\
\hline & & 80 & $267 \mathrm{nM}$ \\
\hline & & 160 & $533 \mathrm{nM}$ \\
\hline \multirow{6}{*}{$8 \mathrm{~nm}$} & \multirow{6}{*}{1,200 ligands } & 5 & $4.18 \mathrm{nM}$ \\
\hline & & 10 & $8.35 \mathrm{nM}$ \\
\hline & & 20 & $16.7 \mathrm{nM}$ \\
\hline & & 40 & $33.3 \mathrm{nM}$ \\
\hline & & 80 & $66.7 \mathrm{nM}$ \\
\hline & & 160 & $133 \mathrm{nM}$ \\
\hline
\end{tabular}

Figure S5. a) Example calculations of the concentration of the 2, 4 and $8 \mathrm{~nm}$ AuNPs necessary to give a ligand concentration of $80 \mu \mathrm{M}$. b) Concentrations of different sized AuNPs used in order to obtain the specified ligand concentration. ${ }^{1}$ 
a)

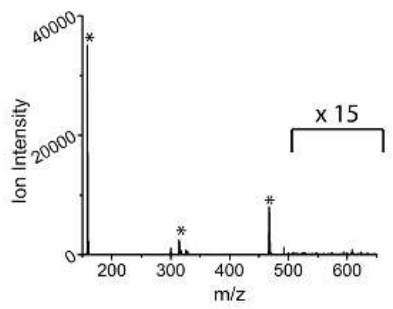

d)

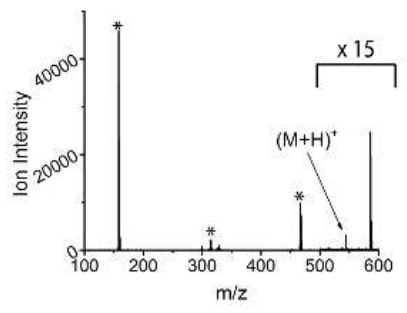

g)

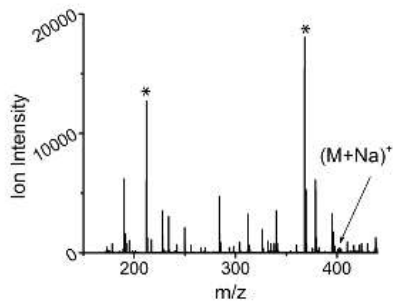

j)

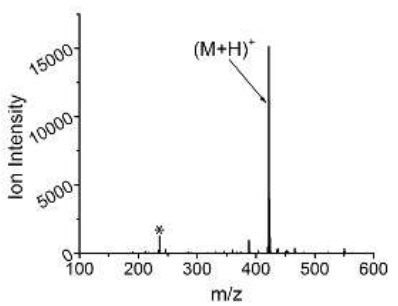

b)

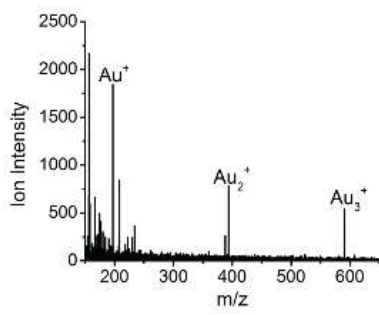

e)

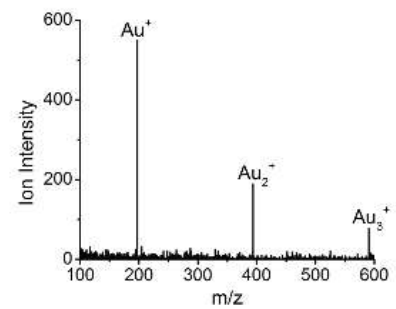

h)

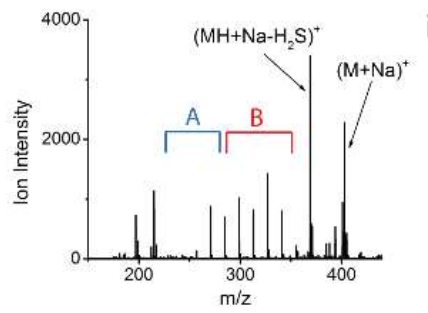

k)

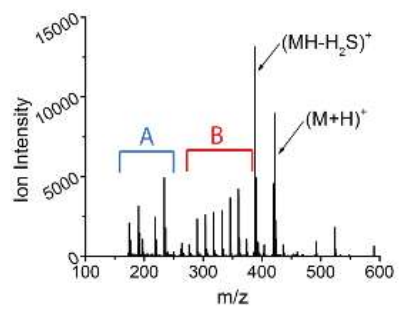

c)

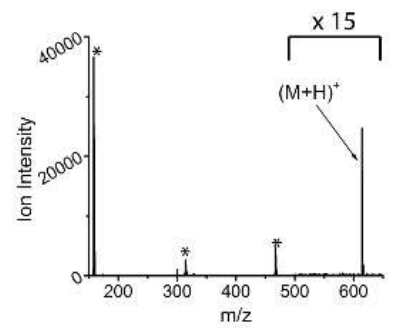

f)

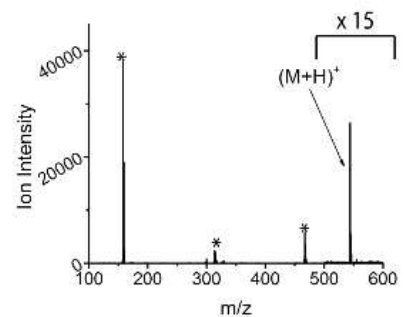

i)

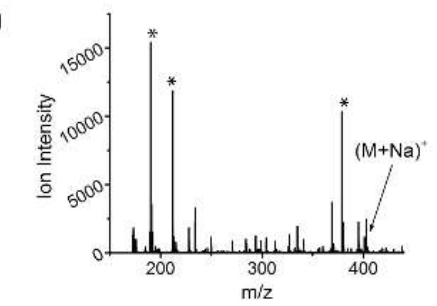

I)

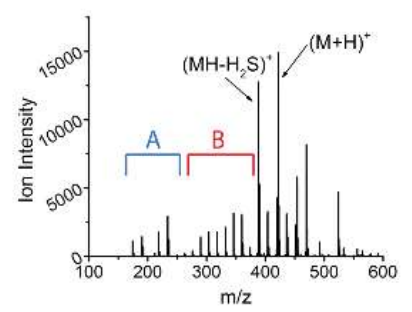

o)

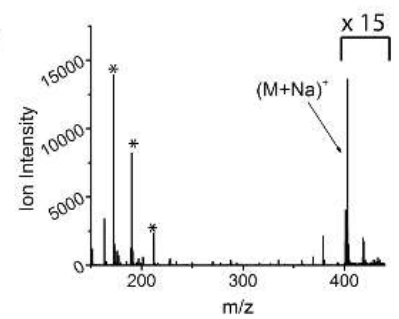

Figure S6. Mass spectra of $80 \mu \mathrm{M}$ free ZNP3 ligands analyzed with $10.2 \mathrm{mg} / \mathrm{mL}$ DAN (a), $1 \mu \mathrm{M}$ ZNP3 AuNPs analyzed by LDI (b), $1 \mu \mathrm{M}$ ZNP3 AuNPs analyzed with $10.2 \mathrm{mg} / \mathrm{mL}$ DAN (c), $80 \mu \mathrm{M}$ free ZNP2 ligands analyzed with $10.2 \mathrm{mg} / \mathrm{mL}$ DAN (d), $1 \mu \mathrm{M}$ ZNP2 AuNPs analyzed y LDI (e), $1 \mu \mathrm{M}$ ZNP2 AuNPs analyzed with $10.2 \mathrm{mg} / \mathrm{mL}$ DAN (f), $80 \mu \mathrm{M}$ free TEGOH ligands analyzed with $2.5 \mathrm{mg} / \mathrm{mL}$ CHCA $(\mathrm{g}), 1 \mu \mathrm{M}$ of $2 \mathrm{~nm}$ TEGOH AuNPs analyzed by LDI (h), $1 \mu \mathrm{M}$ of $2 \mathrm{~nm}$ TEGOH AuNPs analyzed with $2.5 \mathrm{mg} / \mathrm{mL}$ CHCA (i), $80 \mu \mathrm{M}$ free TTMA ligands analyzed with $0.25 \mathrm{mg} / \mathrm{mL}$ CHCA (j), $1 \mu M$ TTMA AuNPs analyzed by LDI (k), $1 \mu \mathrm{M}$ TTMA AuNPs analyzed by $0.25 \mathrm{mg} / \mathrm{mL}$ CHCA (I), $2 \mu \mathrm{M}$ of $2 \mathrm{~nm}$ TEGOH AuNPs analyzed with $2.5 \mathrm{mg} / \mathrm{mL}$ CHCA $(\mathrm{m}), 2 \mu \mathrm{M}$ of $4 \mathrm{~nm}$ TEGOH AuNPs analyzed with 2.5 $\mathrm{mg} / \mathrm{mL}$ CHCA (n) and $2 \mu \mathrm{M} 8 \mathrm{~nm}$ TEGOH AuNPs analyzed with $2.5 \mathrm{mg} / \mathrm{mL}$ CHCA (o). The peaks indicated by $A$ result from the successive losses of ethylene glycol units from the ligand, while the peaks indicated by $B$ result from the successive losses of methylene groups from the intact ligands. 
a)

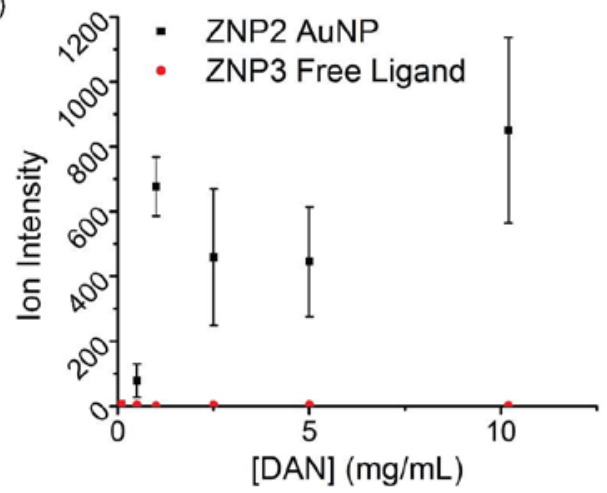

b)

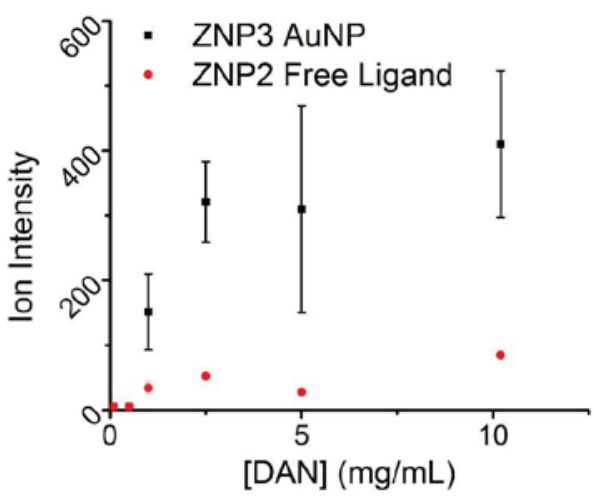

Figure S7. MALDI ion intensities at various concentrations of 1,5-diaminonaphthalene (DAN) of a mixture of a) 1 pmol ZNP2 AuNPs and 80 pmol free ZNP3 ligands (not attached to a gold core) and b) 1 pmol ZNP3 AuNPs and 80 pmol free ZNP2 ligands (not attached to a gold core).

\section{References}

(1) Mei, B. C.; Oh, E.; Susumu, K.; Farrell, D.; Mountziaris, T. J.; Mattoussi, H. Langmuir 2009, 25 (18), 10604-10611. 